DOI: 10.11606/issn.2238-3867.v15i2p320-331

sala preta

ppgac

Dossiê espetáculo: Christiane Jatahy

\title{
0 anseio de imagem na cultura contemporânea através do espelho de Tchekhov
}

\section{Aiming images in contemporary culture through the mirror of Tchekhov}

\section{Ismail Xavier}

Ismail Xavier

Doutor em Estudos de Cinema pela New

York University e professor associado da

Universidade de São Paulo.

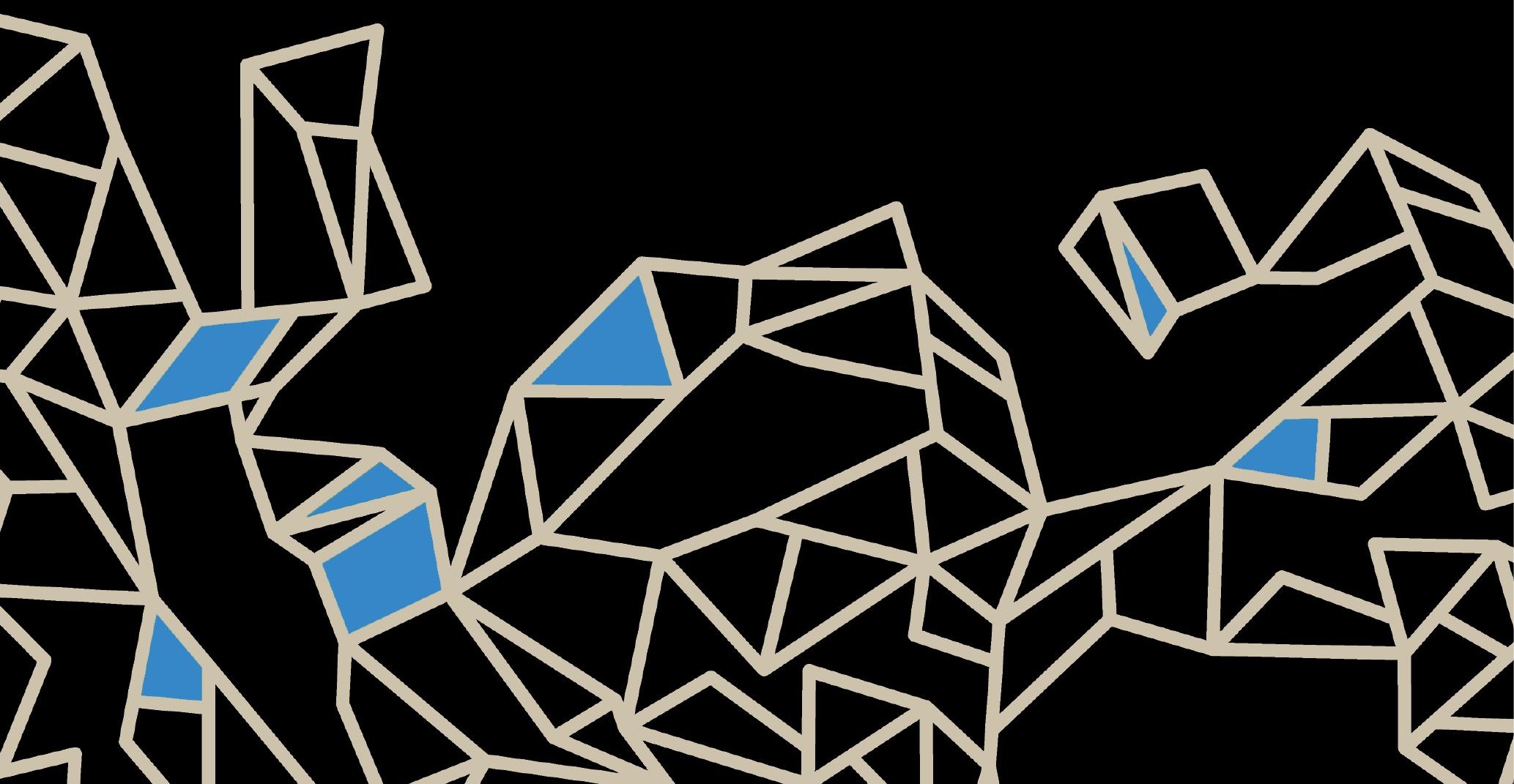




\section{Resumo}

A encenação de As três irmãs, de Anton Tchekhov, dirigida por Cristiane Jatahy explicita em sua abertura que se trata de um espetáculo que não visa à encenação do texto do dramaturgo, mas sim a um diálogo com sua obra, conduzido com liberdade.

Palavras-chave: Imagem, Vídeo, Cinema-teatro.

\section{Abstract}

The Three Sisters by Anton Chekhov, directed by Cristiane Jatahy, explicits that it is a work that does not intend to stage the playwright's text, but a dialogue with him, conducted with freedom.

Keywords: Image, Video, Movie-theater.

A encenação de As três irmãs, de Anton Tchekhov, dirigida por Cristiane Jatahy, explicita em sua abertura que se trata de um espetáculo que não visa à encenação do texto do dramaturgo, mas sim a um diálogo com a sua obra, conduzido com liberdade.

Sentadas num sofá e de frente para a plateia, as três atrizes oferecem as coordenadas do espetáculo numa conversa que cita o esquema dos talk shows da TV e assume seu tom descontraído na informação de que há outra plateia que acompanhará o desenrolar da ação numa tela, ação transmitida "em tempo real" como se costuma dizer, a partir de câmeras de vídeo localizadas no próprio palco e ao fundo da sala, atrás de nós (aqueles que estão no espaço do teatro e face a face com o palco italiano).

No campo das inserções de operações do cinema no palco teatral, $E$ se elas fossem para Moscou? (2015) definiu uma escolha original face à multiplicidade de experiências já exploradas. Não se vale somente de projeções de imagens em movimento numa tela localizada ao fundo do palco, centralizada para o olhar da plateia. Essa é uma opção que, desde Eisenstein e outros encenadores das vanguardas históricas, constituiu um repertório retomado ao longo do século XX, algo que ampliou seu lugar nas performances contemporâneas voltadas para a interação entre os espaços: o do performer e seu público, e o da ação feita presente na tela. Na encenação de Cristiane Jatahy, 
vale outra opção, marcada pelo lance original de separar o que é a experiência da plateia diante do palco italiano e o que é a experiência daquela que, em outra sala, assiste a um filme que, no mesmo momento, traz a sucessão das imagens produzidas pelas figuras que, misto de cinegrafista e personagem, se movem no palco, ora assumindo a posição de operadores de câmera e/ ou organizadores do cenário, ora tendo seu gesto de filmar fazendo parte de sua ação como personagens, ora interagindo com as outras personagens sem mediações. Este é um marco decisivo, pois incide diretamente na forma como a encenação encaminha um debate sobre a relação entre nosso tempo presente e o final de século XIX de Tchekhov, a partir dos motivos dramáticos (e antidramáticos) que põem em movimento a cena.

Já na abertura, há atenção explícita nas indagações sobre a natureza do espetáculo a que as duas plateias estão assistindo, uma vez descrito o esquema de encenação adotado. Um mote na conversa da abertura é a questão da "dificuldade de mudar", reinventar-se, desafio que ganha sua metáfora gravitacional no grande salto, a partir de uma plataforma em que estamos sempre instáveis, entre o empurrão do passado e o travo diante da vertigem no desconhecido, o vazio que no mesmo impulso atrai e atemoriza.

Atrás das três irmãs no sofá, a cenografia já exibe os nichos que vão acolher tal jogo de atração e repulsa, com destaque para o que chamarei aqui de "piscina-aquário", o pequeno reservatório de vidro em que as irmãs farão suas imersões, cada qual à sua vez, num campo de plena segurança que não se põe no mesmo eixo semântico que o salto no vazio, mas num jogo de encaixe no qual o meio aquático vale como campo em que cada uma delas terá seu refúgio em momento estratégico de introspecção, confronto consigo mesmas nesse ambiente não isento de associações uterinas que dá nova conotação a motivos que sopram do texto de Tchekhov. A ideia de aquário talvez me tenha ocorrido pelo lugar dessa minipiscina no cenário, alimentada também por uma curiosa metáfora da crítica que já associou o mundo enclausurado numa tela de cinema a um aquário, dada a sua separação radical face ao espaço exterior da sala e sua pregnância interior como pequeno cosmos. Essa associação talvez tenha ganhado força quando assisti a uma das versões da encenação filmada, na qual os planos próximos do rosto das atrizes dentro da água trazem aquele efeito de deformação que costumamos obser- 
var nos peixes; enfim, um detalhe que teve um efeito de reforço que, nesse caso, se ajusta à deliberada procura do cinema (ou do vídeo) como estrutura de percepção incorporada na encenação. Comentarei adiante a experiência de quem está integrado à plateia assentada no espaço do teatro, que vê a filmagem, mas não seu resultado, ao contrário dos que estão na sala assistindo ao filme produzido pelas câmeras no palco, geradoras do chamado "olho variável" na sucessão de pontos de vista criados pelo registro. ${ }^{1}$

Ao fundo, para além do "aquário", se destaca a paisagem que terá também suas alterações ao longo da peça, pondo-se como contraponto à dominante funcional de vazio, paredes móveis e poucos objetos de cena que modulam o espaço das interações entre as personagens. Num canto do palco, se destaca uma mesa com copos e garrafas a anunciar um momento convivial mais festivo que virá. No centro do palco, vemos uma câmera de vídeo indicada por Olga, aparelho a sinalizar que o diálogo entre teatro e cinema (vídeo) é dado estruturante da encenação, motivo central que também solicita a relação mais livre com a peça de Tchekhov, tal como é de imediato anunciado.

Aqui, vale a pergunta: como pensar os motivos que dão impulso às formas de ação das três irmãs no texto de Tchekhov em função de seu lugar no mundo, e sua relação com os motivos que impulsionam as três irmãs que se expõem no palco da encenação de Jatahy?

Digamos que tais motivos não são idênticos, mas um elo se afirma entre a encenação e o texto, feito de convergências expressas nas cenas em que o diálogo (ou monólogo) expõe modos de interação e de pensamento afinados ao estado de espírito das personagens de Tchekhov. Há, porém, diferenças fundamentais neste espetáculo cuja tônica é dada pelas falas de fatura recente. Embora o autor russo seja a referência, compõem-se com liberdade situações alusivas às que se desenham na peça original. No geral, a performance se ajusta a uma intervenção constante de objetos de cena e dispositivos bem

1 O registro da câmera produz imagens vistas de perto, detalhes, e pode fazer o jogo entre o que está em campo (visível no quadro) e o que está fora de campo para produzir efeitos de sentido usando, por exemplo, a combinação de um rosto em primeiro plano e com um diálogo off, o que produz uma relação entre imagem e som (para a plateia do filme) distinta da oferecida à plateia no teatro. Sabemos da diferença de efeito e de sentido quando vemos fragmentos de um corpo, detalhes isolados de um gesto. A sucessão de planos de um filme antecipa de forma mais enfática para o espectador as diferentes maneiras de relacionar o visível e o não visível, o que se dá também no teatro, mas de outras formas. 
típicos ao nosso tempo. Pontuando a ação dramática, há um conjunto de "peças de conversação" com o público e lances coreográficos que dominam o palco e incorporam o repertório musical pop da mídia contemporânea que embala as protagonistas, especialmente Irina, nesse circuito consonante com a presença de aparatos de som e imagem que interagem com as atrizes de forma a dotar a cena de uma feição particular (e aí essencial) trazida pela teatralidade peculiar à experiência contemporânea e seus espelhamentos eletrônicos. Nesse sentido, o principal a sublinhar não é simplesmente o tempo que separa a composição do texto e a encenação de hoje, gerador daquela usual distância de que estamos conscientes quando assistimos a uma "adaptação" atualizadora. No caso, ao projetar a experiência das três irmãs para o século XXI, a ênfase na presença dos aparatos (câmeras, telefones celulares) torna-se uma operação central que envolve a relação não apenas entre teatro $e$ cinema, mas entre o "teatro de sociedade" de ontem e este de hoje, catalisado pelas novas tecnologias de imagem e som.

\section{As personagens em cena: motivos recorrentes}

No plano das convergências com Tchekhov, as três irmãs, ora encenam diretamente, ora comentam, nas conversas com a plateia, o desencanto associado à pobreza de experiência, à melancolia do tempo que passa sem colorido e densidade. De início, tudo parece menos dolorido para Irina, a mais jovem que, de qualquer modo, não deixará de partilhar o mal-estar das irmãs, embora menos atingida pelo irremediável das decisões já tomadas, seja a do casamento frustrado de Maria ou a da prisão construída pelo senso de dever de primogênita vivido por Olga em sua administração do legado familiar. Ainda na idade dos espasmos de alegria juvenil, Irina em seu percurso de figura autocentrada e carente de mimos leva longe demais sua ansiedade performática potencializada pela presença das câmeras em seu campo de percepção. Ora filma, ora se exibe; alargando seu espaço e visibilidade, até que o impulso de se apropriar do vestido de Maria gera o embate, atiça rivalidades e se faz conflito aberto que Olga, a administradora, não consegue impedir, tal como o desdobramento das pequenas catarses que terminam por enredar a mais jovem em artimanhas do desejo que deflagram a sua própria crise. No primeiro 
ato, ela se apresenta como porta-voz da utopia, com seu discurso de construir um futuro melhor, tornar a sociedade mais justa. Um espírito que parece embalado pelo que há no mundo de promessas ingenuamente formuladas mostrará sua outra face no segundo ato do espetáculo, de modo a incluir em suas polaridades o contraponto de um namorado "episto(celu)lar" que se consome em gestos de afetação trágica de viés sadomasoquista que culminam num lance suicida que a mise-en-scène confina ao espaço off, menos para seguir a prescrição clássica de um decoro a respeitar no campo visível, mais para deixar as pregações do jovem via celular num plano de virtualidade inconsequente destinada ao esquecimento.

A questão de Maria é a desilusão do casamento efêmero alimentado pela tola idealização da figura masculina objeto de desejo, uma postura que partilhou com a expectativa da família, dentro do protocolo, ainda vigente, de uma tradição patriarcal produtora e protetora da inocência feminina, a despeito das desenvolturas próprias à modernidade tardia bem presentes no espaço em que essas moças vivem. Inconformada com esse descompasso diante das interações mais velozes de seu tempo, Maria carrega as tensões que sua memória do fracasso lhe impõe, em meio a suas também vagas projeções de um futuro melhor nos momentos de conversa fiada com as irmãs. Figura de alta tensão, desde o início, vive o impasse dos ressentidos e se diz "em luto pela minha vida".

Olga concentra, mais do que as irmãs, o lado patético da insatisfação e do confinamento trazido pelas renúncias a que se obriga em nome do legado familiar a que dá suporte até o fim. Irmã mais velha enredada na ética de mãe substituta, guardiã da tradição, sempre a cuidar dos escombros do passado, paga o preço de um sentimento de desperdício da vida bem próprio a quem não se sente objeto de desejo, terreno em que se alimenta de um suposto "haver sido". Sua presença sentenciosa é central nas falas do sofá, mas também se faz foco de solilóquios embebidos de angústia, reflexões em que liga a impostação da fala e a emoção em cantos mais sombrios do palco, nicho das perdas irremediáveis e da tragédia pessoal.

Um gradiente de luz se compõe ao longo da peça, das águas claras da celebração do aniversário de Irina no primeiro ato ao momento das sombras 
que favorecem as projeções dos fantasmas e levam a expressões mais cabais do mal-estar, seja na resposta melodramática de Irina ao fracasso da sua festa, seja no desespero de Maria quando se dissolve ex abrupto a fantasia com Alex, o jovem amigo da família, após longa encenação de um encontro sexual coadjuvado pela câmera-na-mão do próprio Alex, um objeto indispensável, e de certo modo central, na relação. A crise de Irina e a explosão de Maria, quando abandonada no palco por Alex, compõem o momento tônico de um acontecer, de uma presença enérgica dos corpos em cenas do confronto que, intensas, temperadas de agressões e pragas, não encontram desdobramento, embora sejam um contraponto calculado às amenidades do primeiro ato, momento de celebrações. Há, sem dúvida, nesse momento tônico um quê de hora da verdade que desfaz a aparência das amorosidades fraternas que se estendiam, inclusive, à humanidade, quando todos, lado a lado na descontração da festa, viveram o momento das mensagens edificantes dirigidas ao futuro em falas diretas para a câmera (potencial forma de sair da irrelevância).

$\mathrm{Na}$ ondulação do clima, a hora da verdade do segundo ato passa da extroversão à interiorização, e a tensão entre as personagens se desloca por caminhos que levam a um teatro de sombras que vem dar uma tonalidade gótica ao passeio solitário de Olga à luz de uma vela e à cena do carrinho de bebê com que ela termina por interagir, evocação de seu desejo frustrado de ter um filho, sequência que termina em solilóquio com a renovada pergunta "quem sou eu?" Resta-lhe o isolamento da recomposição "aquariana", enquanto no fundo do palco se completa uma fala de Irina sobre a travessia do espelho. A lenta cena de Maria a sair do torpor nessa espécie de pós-tudo define passagem de pontuação mais silenciosa que compõe uma atmosfera, não propriamente uma resolução dramática. Essa, em verdade, não estava em pauta, pois é outra a natureza do jogo. Cabe ao momento gótico de introversão se inverter na descontração final marcada pela reposição da luz e pelo preparo de um desfecho que retoma a conversa da abertura. E o faz não sem certa ironia nas indagações sobre o não lugar representado pelo significante Moscou, aqui acompanhadas de imagens clichês de uma suposta partida de Irina para a viagem que vemos (nós da plateia do teatro) numa tela ao fundo do palco. 
Este momento de projeção de imagens ajuda a cortar uma pedagogia já em excesso presente nas falas reiteradas sobre o passado, o futuro e a dificuldade de mudar. Quando a atenção converge para a imagem das irmãs olhando para a câmera, há uma reposição sorridente, porém sem muito élan, de um traço de união apto a sublinhar quanto o assombro do vazio, embora tenha razões distintas, foi um traço comum às três ao longo da encenação em que o espaço da casa adquiriu sua feição sui generis. Relativamente isolado, tal espaço está fora do centro quando se pensa a circulação e a vida agitada nas malhas da cidade, o que torna as imagens projetadas nesse final um aceno a um mundo externo que, pelo toque de leveza na pantomima, confere graça a um anelo de viagem já saturado de conotações. O dado central a ressaltar nessa relação interior-exterior está no próprio espaço da casa ao longo da encenação, onde uma crônica da vida contemporânea se expressa na onipresença de eletrônicos que pontua o cotidiano de personagens "conectadas", devendo ser outra a noção de espaço a trabalhar se quisermos falar em isolamento. Essa crônica se articula à opção decisiva pela forma de metateatro gerada pela filmagem em pleno palco.

Dito isso, vale observar que minha ênfase nesse comentário não recai sobre a exploração do cotejo cinema-teatro que resulta na adoção de uma dupla plateia, embora a filmagem da peça ofereça à plateia da outra sala um filme que é uma dimensão fundamental do experimento. Sem dúvida, para a fruição completa do projeto, vale somar as duas experiências que não podem ser simultâneas, a da encenação direta e a do filme. Entre uma e outra sala, tudo muda, pois a linguagem do filme é criadora de outro espetáculo que ressalta aspectos da experiência das personagens que não são acessíveis à plateia que está na sala do teatro. O que prefiro ressaltar, pois mais decisivo no plano do diálogo com Tchekhov, é o efeito das operações de filmagem na própria percepção de quem está na sala do teatro, já que o efeito desse dispositivo vai além da função do contrarregra e de outras providências visíveis que expõem a fatura, sublinhando o desenho da encenação e antecipando o movimento das personagens. O essencial neste caso é que as descontinuidades que a filmagem produz no andamento da ação se embaralham com a função assumida pelas câmeras, entre outros aparatos técnicos, no plano da diegese (mundo da ficção que se representa). Reconhecidos e mobilizados 
pelas personagens, esses aparatos incidem sobre as relações entre elas na movimentação pelo palco e marcam as conexões de Irina e Maria com o mundo extracena, terreno em que não falta uma referência irônica aos aplicativos da "paquera" eletrônica que teriam "eliminado" a solidão.

Ao lembrar desse potencial de fluência nas conexões viabilizadas pelas técnicas de comunicação atuais, a encenação minimiza o peso daquele tom bucólico da casa no campo insinuado pela paisagem de fundo. Esta, sem naturalismo, modulada por efeitos técnicos, é mais um componente da cenografia escalonada que passa pela parede modulada e flexível que dinamiza o espaço das cenas, de modo a tornar a piscina-aquário, o campo mais efetivo de imersão e isolamento. Como observei, o aquário é o laboratório de introspecção equalizador das sensações; no limite, um espaço de gozo que se pode dizer regressivo nesse percurso em que o desafio da mudança - o salto no vazio - está reduzido às palavras que evocam destinos utópicos ou expressam a crispação própria a um senso da derrota já intuída. Não admira que os momentos de explicitação do dissenso entre elas componham uma coleção de rompantes de raiva - de si e do Outro -, nos quais cada qual termina por expor a baixa autoestima, mesmo que em suas performances enquanto corpos em cena tenham exibido momentos mais afirmativos de glamour e sedução, catalisados pela variedade de olhares públicos (as câmeras) que as cercam no próprio palco, ou seja, no espaço da casa.

Estar "sob os olhares de" é aqui a pedra de toque na interação com este Outro, ao mesmo tempo indefinido e incontável, que mobiliza as personagens, Irina e Maria mais desenvoltas do que Olga, como cinegrafistas a compor seu filme de família, ou como moças performáticas, na criação de imagem no confronto com as câmeras, esses pontos de mediação entre o aqui e o alhures, entre o presente e o futuro, mais do que tudo superfícies que corporificam as dobras do "si mesmo". É um efeito que se amplia no palco, pois torna as ações uma performance redobrada: a da atriz para nós (plateia) inclui a da personagem, esta que nesse caso visa não somente os olhares de seus convivas em cena, mas também o olhar estruturante, porque interno à cena, de um aparato que potencializa o desejo de ser imagem, de "fazer cena".

E há outras instâncias, ora mais simples, quando, por exemplo, Irina, feliz, "filma sem parar com a câmera que ganhara de presente do pai”; ora mais 
complexas, como no caso da cena de Maria, a certa altura da peça, portar uma câmera na mão e passar a se filmar no monólogo de rejeição e desqualificação do marido, dirigindo-se a um "tu" ausente da cena. Observada pelas irmãs sem que estas reconheçam a presença da câmera (aqui, joga-se com a ambiguidade dessa diegetização do aparato) é chamada a explicar o que está fazendo ali, sozinha, naquele canto do palco junto da plateia, onde foi pedir auxílio de um espectador na administração da imagem de seu solilóquio. Seria redutor observar essa fala direta com a câmera como um recado, espécie de comunicação diferida, equivalente a uma carta a esse "tu" ausente, pois o que está aí implicado de forma mais direta é uma impulsão de fala de si para si, relação especular de desabafo vivido neste teatro interior que agora encontra no aparato o lugar por excelência. A câmera, tal como o espelho, se mostra um laboratório do desejo, um estar cá e lá ao mesmo tempo, no espaço real e no virtual, alterando a forma e o estatuto do monólogo interior, da imprecação e do falar consigo mesmo que simula um "tu", interlocutor imaginário que atiça a fala e o sentimento nesse teatro em que o sujeito é ator e espectador, foco da enunciação e da réplica.

Em E se elas fossem para Moscou?, as situações de diálogo explícito com a plateia e a quebra da quarta parede são um fator de descontração do espetáculo, mesmo quando há uma longa peroração, misto de queixa e invocação da personagem (Irina). E os solilóquios se compõem de forma a lembrar que nossa relação com o imaginário tem uma boa metáfora na fala direta com a câmera como nova forma de expressar o senso de que o falar consigo é falar com um outro. Estamos estruturalmente identificados com esta nova forma: temos o aparato dentro de nós a embaralhar vida interior e teatro em sociedade.

Desse modo, Jatahy insere na estrutura da encenação o cotejo entre aquele "teatro em sociedade" tal como um exímio observador como Tchekhov construiu em suas peças quando definiu a performance de cada personagem nos termos da sociedade que colocou em foco, e o "teatro em sociedade" tal como vivido hoje, incluindo a mediação de uma variedade de espelhos que a tecnologia disponibilizou, dispositivos catalisadores de performances que têm produzido novas formas de narcisismo e construção de imagem com incidência direta nas formas de subjetivação e de interação social. 
Essa experiência assinala que, apesar dessa distância, mais do que tudo evidenciada na cultura pop e nos aparatos, há um substrato comum no mal-estar dessas moças que faz a ponte entre texto e encenação identifica em certo sentido a estrutura de sentimentos que molda a sua frustração nas relações. $O$ fantasma da irrelevância habita os dois mundos. O primeiro, lá na passagem do século XIX ao XX, tem passo mais lento, é mais discreto, introvertido, mas não tanto, pois é próprio das irmãs e de seus interlocutores serem performáticos em sociedade. O segundo é hiperativo, histérico, exibicionista: como encontrar um lugar para a reflexão neste mundo acelerado?

A diferença no significado da cidade de Moscou altera o sentido dos anelos de mudança - lá era a nostalgia que tinha a referência da infância, do passado vivido e perdido, o senso de que a vida na província era um exílio. $\mathrm{Na}$ encenação de hoje, permanece o significante Moscou, mas este muda de sentido, é um não lugar. Há como pressuposto dessa ida a Tchekhov a sugestão de que as duas situações podem, no fundo, produzir posturas afinadas, apesar de suas diferenças de condição e do que nelas se concebe como sonho. Em particular, é nítida a diferença entre buscar tal território do sonho no passado, no lugar de origem, ou buscar tal território em um lugar, algo que se constitui a partir de encantamentos imaginários nada distantes de uma afetação pelo que conota alteridade. Temos aí algo nas antípodas do sentido que tem Moscou para as figuras do dramaturgo, como se a formação atual não mais estabelecesse a infância e sua memória como ponto de referência, nos atando a um eterno presente e sua ciranda de clichês, embora em tudo pareça que a tecnologia nos faz sempre lembrar a velocidade das mudanças.

Vale aqui, a partir do espelho invertido de Tchekhov, um debate sobre a formação da subjetividade contemporânea às voltas com o labirinto das construções identitárias, seus fatores, seus desencontros e seus pontos-limite problemáticos: num polo, a fixação no passado, uma obsessão identitária regressiva; em outro, a euforia apressada com a ideia de plasticidade infinita do sujeito quando a colagem de imagens heteróclitas pode fazê-lo perder o senso do lugar de onde fala ou do seu lugar de ação, ou de interrogação, caldo de cultura para o autoexílio, o desencanto e a pobreza de experiência. 


\section{Referências bibliográficas}

E SE ELAS fossem para Moscou? Baseado no texto As três irmãs, de Anton Tchekov. Adaptação, Direção e Roteiro: Christiane Jatahy. Cia. Vértice de Teatro, 2015.

Recebido em 29/10/2015

Aprovado em 29/10/2015

Publicado em 21/12/2015 